OPEN ACCESS

Edited by:

Enrico Baruffini,

University of Parma, Italy

Reviewed by:

Christine E. McLaren,

University of California, Irvine,

United States

Lyle Gurrin,

The University of Melbourne,

Australia

${ }^{*}$ Correspondence:

Xiaojuan $\mathrm{Ou}$

252546811@qq.com Jidong Jia

jia_jd@ccmu.edu.cn

Specialty section: This article was submitted to

Genetic Disorders,

a section of the journal

Frontiers in Genetics

Received: 16 October 2019

Accepted: 23 January 2020

Published: 21 February 2020

Citation:

Zhang W, Wang X, Duan W, XU A, Zhao $X$, Huang J, You $H$, Brissot $P$,

Ou X and Jia J (2020) HFE-Related Hemochromatosis in a Chinese

Patient: The First Reported Case. Front. Genet. 11:77.

doi: 10.3389/fgene.2020.00077

\section{HFE-Related Hemochromatosis in a Chinese Patient: The First Reported Case}

\author{
Wei Zhang ${ }^{1,2,3}$, Xiaoming Wang ${ }^{1,2,3}$, Weijia Duan ${ }^{1,2,3}$, Anjian $X^{1,3,4}$, Xinyan Zhao ${ }^{1,2,3}$, \\ Jian Huang ${ }^{1,2,3,4}$, Hong You ${ }^{1,2,3}$, Pierre Brissot ${ }^{5}$, Xiaojuan Ou ${ }^{1,2,3^{*}}$ and Jidong Jia ${ }^{1,2,3 *}$ \\ ${ }_{1}^{1}$ Liver Research Center, Beijing Friendship Hospital, Capital Medical University, Beijing Key Laboratory of Translational \\ Medicine on Liver Cirrhosis, Beijing, China, ${ }^{2}$ Clinical Research Center for Rare Liver Diseases, Capital Medical University, \\ Beijing, China, ${ }^{3}$ Liver Research Center, National Clinical Research Center for Digestive Diseases, Beijing, China, \\ ${ }^{4}$ Experimental Center, Beijing Friendship Hospital, Capital Medical University, Beijing, China, 5 Institut NuMeCan, InsermU- \\ 1241, University of Rennes1, Rennes, France
}

HFE-related Hemochromatosis is the most common genetic iron overload disease in European populations, particularly of Nordic or Celtic ancestry. It is reported that the HFE p.C282Y mutation is present in 1/10 people of northern European descent, resulting in one in two hundred people will be homozygous. However, the HFE p.C282Y heterozygosity is virtually absent among East Asians, including Japanese, Koreans, and Chinese. In this article, we report a case of HFE-related hemochromatosis caused by compound heterozygosity HFE p.C282Y/p.R71X. This is the first report of hemochromatosis associated with HFE p.C282Y mutation in China.

Keywords: HFE, compound heterozygosity, hemochromatosis, iron overload, Chinese

\section{BACKGROUND}

HFE-related hemochromatosis $(\mathrm{HH})$ is the most common genetic iron overload disease in European populations, particularly of Nordic or Celtic origin (Powell et al., 2016; Brissot et al., 2018). The most common mutation in the HFE gene is p.C282Y. It is reported that the HFE p.C282Y mutation is present in $1 / 10$ people of northern European descent, resulting in one in two hundred people that will be homozygous (Powell et al., 2016). However, the HFE p.C282Y mutation is virtually absent among East Asians, including Japanese (Ikuta et al., 2017), Koreans (Choi et al., 2002), and Chinese (Lin et al., 2007). To our knowledge, only one case of hemochromatosis associated with HFE p.C282Y mutation has been reported in Japan (Sohda et al., 2001).

In this article, we report a case of hereditary hemochromatosis caused by compound heterozygosity HFE p.C282Y/p.R71X. This is the first report of hemochromatosis associated with HFE p.C282Y mutation in China.

\section{CASE PRESENTATION}

A 28-year-old male was admitted to our department because of lasting abnormal liver function tests dating back eight years, without any clinical symptoms. He denied taking supplemental iron or consuming excess alcohol. His BMI was $24.6 \mathrm{~kg} / \mathrm{m}^{2}$ and his physical examination was normal. Liver 
biochemistry results were as follows: alanine aminotransferase (ALT), 106 IU/L (normal: 5-40 IU/L); aspartate aminotransferase (AST), 41 IU/L (normal: 8-40 IU/L); alkaline phosphatase (ALP), $77 \mathrm{U} / \mathrm{L}($ normal: 40-150U/L); gammaglutamyltransferase (GGT), 19 IU/L (normal: 11-50 IU/L); and normal total and conjugated bilirubin (TB/DB), 8.8 and 3.4 $\mu \mathrm{mol} / \mathrm{L}$, respectively. His fasting glucose: $4.64 \mathrm{mmol} / \mathrm{L}$. Lipid profile: total cholesterol, $4 \mathrm{mmol} / \mathrm{L}$ (normal: 3.90-5.20); triglyceride, $1.8 \mathrm{mmol} / \mathrm{L}$ (normal: 0.57-1.70); low density lipoprotein cholesterol, $2.30 \mathrm{mmol} / \mathrm{L}$ (normal: 2.34-3.12). Uric acid, $351.1 \mu \mathrm{mol} / \mathrm{L}$ (normal: 178-416). Serum markers for viral hepatitis and autoimmune liver diseases were negative. Plasma iron indices: iron $38 \mu \mathrm{mol} / \mathrm{L}$ (normal: $<25 \mu \mathrm{mol} / \mathrm{L}$ ), transferrin saturation $86.4 \%$ (normal: < 45\%), and ferritin $3033 \mathrm{ng} / \mathrm{ml}$ (normal: < $300 \mathrm{ng} / \mathrm{ml}$ ). Magnetic resonance imaging (MRI) of the abdomen showed that the liver $\mathrm{T} 2^{*}$ value was $1.16 \mathrm{~ms}$, which means severe iron overload in the liver, and the spleen was devoid of any iron overload. Liver biopsy showed severe iron deposited predominantly in hepatocytes with a decreasing gradient from periportal zone 1 to centrilobular zone 3, and iron deposits in few Kupffer cells (Figures 1A, B). In addition, steatosis of hepatocytes was observed, and there was mild fibrosis with stage $\mathrm{S} 1$.

Genetic analysis was performed in the patient and his parents to determine whether the iron overload was related to hemochromatosis. Informed consent was obtained before taking a blood sample for gene analysis of HFE, HJV, HAMP, TFR2, and SLC4OA1. Genomic DNA was extracted from peripheral blood leukocytes using the Genomic DNA Purification Kit (Qiagen, Valencia, CA). All exons of HFE, HJV, HAMP, TFR2, and SLC40A1 were PCR amplified with their associated boundary regions using the primers described in our previous study ( $\mathrm{Lv}$ et al., 2018). PCR products were sequenced in forward and reverse orientations using an automated ABI3730 DNA sequencer (ABI).

The results showed that the patient had compound heterozygous mutations p.C282Y/p.R71X in the HFE gene (Figure 2A). No mutations were identified in the other four genes. His father and mother carried a heterozygous mutation p.C282Y, p.R71X in the HFE gene, respectively. HFE p.R71X has been reported in a previous study (Beutler et al., 2002). HFE p.R71X is a C-to-T nonsense mutation at cDNA position 211 of the HFE gene, resulting in the substitution of a termination codon for arginine 71 in exon 2 of the HFE gene.

The patient was found to be a compound heterozygote p.C282Y/p.R71X, which was inherited from his father and mother, respectively. His phenotype was typical of HFE-related hemochromatosis. His mother carried a heterozygous mutation p.R71X in HFE gene, with normal plasma liver biochemical tests and iron parameters. His father, who carried a heterozygous

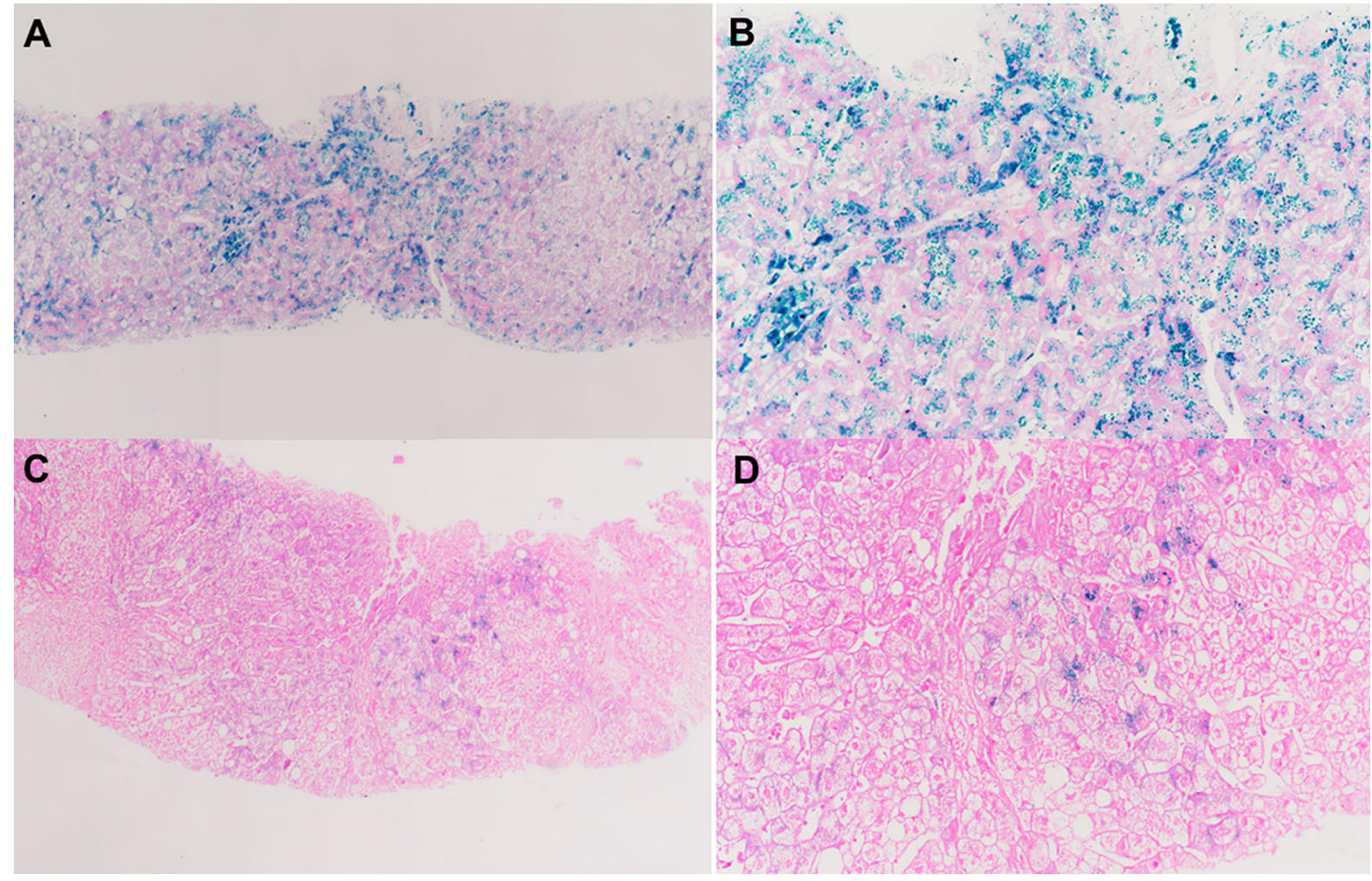

FIGURE 1 | Liver biopsy data. (A, B) Liver biopsy of the hemochromatosis patient associated with HFE p.C282Y/p.R71X. It shows heavy iron accumulation in hepatocytes with little Kupffer cell siderosis. (C, D) Liver biopsy of the patient's father with alcoholic liver disease showing sparse iron deposits in hepatocytes. (A, C) Perls, 20× magnification; (B, D) Perls, 40× magnification. 
A

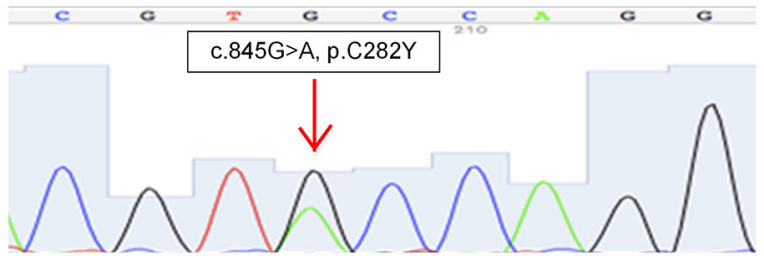

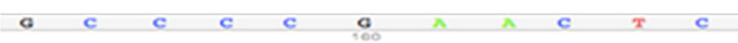

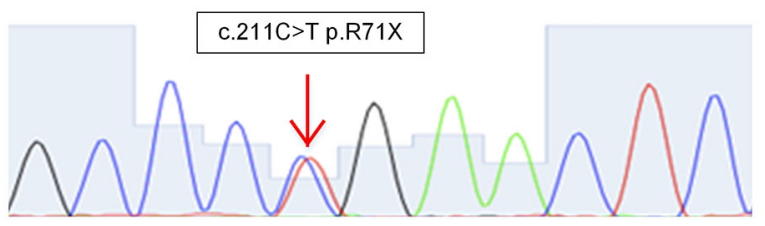

B

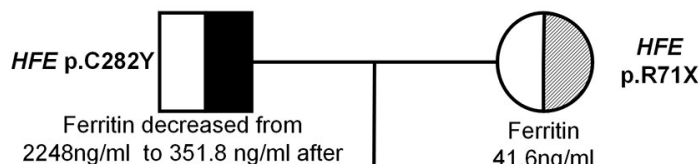

abstinence

HFE p.C282Y/R71X

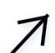

Ferritin decreased from $3033 \mathrm{ng} / \mathrm{ml}$ to

$345 \mathrm{ng} / \mathrm{ml}$ after phlebotomy

FIGURE 2 | (A) Sequence analysis of the HFE gene showing two heterozygous mutations p.C282Y and p.R71X. (B) Pedigree analysis of the family. The patient had compound heterozygous mutations p.C282Y/p.R71X in HFE gene on different alleles, which were inherited from his father and mother, respectively.

mutation p.C282Y in HFE gene, presented some degree of iron overload that could be related to alcoholic liver cirrhosis (liver biopsy is shown in Figures 1C, D). The segregation analysis is shown in Figure 2B. It should be noted that the ancestry of the patient was Chinese for several generations.

According to therapeutic recommendations released by Hemochromatosis International (Adams et al., 2018), a therapeutic phlebotomy (400 $\mathrm{ml}$ of whole blood) was performed every 1-2 weeks. After 32 phlebotomies within one year and two months, $11.8 \mathrm{~L}$ of whole blood were withdrawn from the patient. AST and ALT returned to normal range, and plasma ferritin level decreased to $28 \mathrm{ng} / \mathrm{ml}$. His father's plasma iron parameters decreased significantly after abstinence from alcohol. Clinical data of the patient and his father are summarized in Table $\mathbf{1 .}$

\section{DISCUSSION}

Here we report a case of hemochromatosis associated with compound heterozygous mutation p.C282Y/p.R71X in HFE gene in China. The patient had a phenotype highly suggestive
TABLE 1 | Clinical characteristics and the patient with $\mathrm{HH}$ and his father with secondary iron overload.

\begin{tabular}{|c|c|c|}
\hline & The patient & The patient's father \\
\hline $\begin{array}{l}\text { Lifestyle } \\
\text { habits }\end{array}$ & None & History of heavy drinking \\
\hline Gender & Male & Male \\
\hline ALT (U/L) & 106 & 62.9 \\
\hline AST (U/L) & 41 & 72.8 \\
\hline GGT (U/L) & 19 & 96.8 \\
\hline $\begin{array}{l}\text { Ferritin (ng/ } \\
\text { ml) }\end{array}$ & 3,033 & 2,248 \\
\hline $\begin{array}{l}\text { Skin } \\
\text { pigmentation }\end{array}$ & None & None \\
\hline $\begin{array}{l}\text { Cardiac } \\
\text { disorders } \\
\text { Liver } \\
\text { histology }\end{array}$ & None & None \\
\hline -fibrosis & None & S4 \\
\hline $\begin{array}{l}\text {-iron } \\
\text { overload }\end{array}$ & $\begin{array}{l}\text { Heavy iron deposits in } \\
\text { hepatocytes with a decreasing } \\
\text { gradient from zone I to III. }\end{array}$ & $\begin{array}{l}\text { Mild sparse iron deposits in } \\
\text { hepatocytes }\end{array}$ \\
\hline $\begin{array}{l}\text { Effective } \\
\text { therapy }\end{array}$ & Phlebotomy & Total abstinence from alcohol \\
\hline $\begin{array}{l}\text { Genetic } \\
\text { background }\end{array}$ & HFE p.C282Y/R71X & HFE p.C282Y \\
\hline $\begin{array}{l}\text { Final } \\
\text { diagnosis }\end{array}$ & $\begin{array}{c}\text { HFE related (or type 1) hereditary } \\
\text { haemochromatosis }\end{array}$ & $\begin{array}{l}\text { Secondary iron overload } \\
\text { syndromes related to alcohol } \\
\text { related liver injury }\end{array}$ \\
\hline
\end{tabular}

$A L T$, alanine aminotransferase; AST, aspartate aminotransferase; GGT, glutamyltranspetidase.

of hepcidin deficiency with very high plasma transferrin saturation and severe hepatocyte iron overload on liver biopsy. The genotypic study confirmed the diagnosis of HFE-related hemochromatosis (or hemochromatosis type 1). It should be noticed that one cannot exclude that part of hyperferritinemia was related to a dysmetabolic component since this patient presented some degree of steatosis (Lorcerie et al., 2017).

This case highlighted three important clinical issues. Firstly, this is the first case of HFE-related hemochromatosis in a Chinese patient. It is well known that HFE p.C282Y is very common and responsible for most cases of hemochromatosis in Caucasians (Kowdley et al., 2019). However, HFE p.C282Y has been rarely identified in East Asians in previous studies (Choi et al., 2002; Lin et al., 2007; Ikuta et al., 2017). Furthermore, HFE p.C282Y mutation had been identified neither in a variety of disorders in China such as chronic hepatitis C, nonalcoholic fatty liver disease (Lin et al., 2005), cardiovascular disease (Bi et al., 2013), myelodysplastic syndromes, and aplastic anemia(Nie et al., 2010), nor in general population(Lin et al., 2007). In addition, we recently analyzed 22 patients with primary iron overload and no HFE variants were identified (Lv et al., 2018). Therefore, although very rare, HFE gene mutations should not be ignored as a possible cause of hemochromatosis in Asians.

The second clinical comment concerns the autosomal recessive nature of $H F E$-related hemochromatosis, so that a heterozygous mutation in HFE gene will not lead to hemochromatosis. It has been reported that among HFErelated hemochromatosis, p.C282Y homozygotes accounts for 95\%, p.C282Y/H63D compound heterozygotes and p.H63D 
homozygotes accounts for 4\%, 1\%, respectively (Adams, 2015). However, the responsibility of the latter two genotypes in causing hemochromatosis remains highly debated (Porto et al., 2016). In the hemochromatosis patient here reported, the p.C282Y mutation was found in combination with a nonsense mutation R71X in HFE gene. HFE R71X mutation, resulting in the substitution of a termination codon for arginine 71 in exon 2 of the HFE gene, exerts marked effect on iron homeostasis, as reported in a previous study (Beutler et al., 2002). While the fact that the patient's mother has the heterozygous p.R71X mutation in the HFE gene but is not iron overloaded is clearly consistent with the hypothesis that this single heterozygous HFE mutation alone is not sufficient for iron overload, and it is just a single case.

The third comment relates to the importance of considering both the clinical history and the response to therapy for differentiating hemochromatosis from secondary iron overload. In this study, although both son and father carried a single heterozygous mutation HFE p.C282Y, alcohol turned out to be a key factor in causing increased plasma iron indices in the patient's father since after four months of total abstinence both liver function tests and iron parameters returned to normal. In contrast, our hemochromatosis patient did not have any excessive alcohol consumption and the sole phlebotomy therapy was able to restore normal iron parameters. It is also noteworthy that both son and father were heterozygous for the p.C282Y mutation: this genetic profile could not, a priori, be considered as responsible for iron overload since the vast majority of HFE-related hemochromatosis cases are related to p.C282Y homozygosity. It is precisely the peculiar phenotypic profile of the son which justified pursuing the genetic investigations leading to the finding of another type (this time deleterious) of HFE-related compound heterozygosity. Finally, it should be noted that the phenotypic profile of our patient was close to that described as "juvenile" hemochromatosis (severe iron overload before the age of 30 years).

\section{CONCLUSION}

HFE-related hemochromatosis was identified in a Chinese hemochromatosis patient for the first time. Although very rare in Asians, this diagnostic possibility should not be ignored, given its major importance for the proband him(her)self and for his (her) family. In practice, clinicians should use a combination of

\section{REFERENCES}

Adams, P., Altes, A., Brissot, P., Butzeck, B., Cabantchik, I., Cançado, R., et al. (2018). Therapeutic recommendations in HFE hemochromatosis for p.Cys282Tyr (C282Y/C282Y) homozygous genotype. Hepatol. Int. 12, 83-86. doi: 10.1007/s12072-018-9855-0

Adams, P. C. (2015). Epidemiology and diagnostic testing for hemochromatosis and iron overload. Int. J. Lab. Hematol. 37 Suppl 1, 25-30. doi: 10.1111/ ijlh.12347

Beutler, E., Griffin, M. J., Gelbart, T., and West, C. (2002). A previously undescribed nonsense mutation of the HFE gene. Clin. Genet. 61, 40-42. doi: 10.1034/j.1399-0004.2002.610108.x phenotypic and genotypic information to suggest and confirm the diagnosis of hemochromatosis.

\section{DATA AVAILABILITY STATEMENT}

The raw data supporting the conclusions of this article will be made available by the authors, without undue reservation, to any qualified researcher.

\section{ETHICS STATEMENT}

Written informed consent to publish this case report was obtained from the patient and his family.

\section{AUTHOR CONTRIBUTIONS}

WZ made substantial contributions to conception and design, acquisition, analysis, and interpretation of the data, and involved in drafting the manuscript. XW, WD, AX, XZ, and HY made substantial contributions to the acquisition, analysis, and interpretation of the data. $\mathrm{JH}$ and $\mathrm{PB}$ involved in critically revising the manuscript for important intellectual content. XO and JJ made substantial contributions to conception and design and involved in revising the manuscript critically for important intellectual content, and gave the final approval of the version to be published.

\section{FUNDING}

This study was supported by grants from The Beijing Natural Science Foundation (No.7194254) and The Digestive Medical Coordinated Development Center of Beijing Hospitals Authority (No. XXZ0502).

\section{ACKNOWLEDGMENTS}

We would like to thank the patient and his family for allowing us to publish this case.

Bi, M., Li, B., and Li, Q. (2013). Correlation of hemochromatosis gene mutations and cardiovascular disease in hemodialysis patients. Ann. Saudi. Med. 33, 223 228. doi: 10.5144/0256-4947.2013.223

Brissot, P., Pietrangelo, A., Adams, P. C., Graaff, B. D., Mclaren, C. E., and Loréal, O. (2018). Haemochromatosis. Nat. Rev. Dis. Primers 4, 18016. doi: 10.1038/ nrdp. 2018.16

Choi, S. J., Min, W. K., Chun, S., Park, H., Kim, J. W., Park, C. J., et al. (2002). Frequencies of $\mathrm{C} 282 \mathrm{Y}$ and $\mathrm{H} 63 \mathrm{D}$ mutations and transferrin saturation indices in the Korean population. Clin. Chem. Lab. Med. 40, 689-692. doi: 10.1515/CCLM.2002.118

Ikuta, K., Hatayama, M., Addo, L., Toki, Y., Sasaki, K., Tatsumi, Y., et al. (2017). Iron overload patients with unknown etiology from national survey in Japan. Int. J. Hematol. 105, 353-360. doi: 10.1007/s12185-016-2141-9 
Kowdley, K. V., Brown, K. E., Ahn, J., and Sundaram, V. (2019). acg clinical guideline: hereditary hemochromatosis. Am. J. Gastroenterol. 114, 1202-1218. doi: 10.14309/ajg.0000000000000315

Lin, T. J., Lin, C. L., Wang, C. S., Liu, S. O., and Liao, L. Y. (2005). Prevalence of HFE mutations and relation to serum iron status in patients with chronic hepatitis $\mathrm{C}$ and patients with nonalcoholic fatty liver disease in Taiwan. World J. Gastroenterol. 11, 3905-3908. doi: 10.3748/wjg.v11.i25.3905

Lin, A., Yan, W. H., Xu, H. H., Zhu, M., and Zhou, M. Y. (2007). Analysis of the HFE gene (C282Y, H63D and S65C) mutations in a general Chinese Han population. Tissue Antigens 70, 252-255. doi: 10.1111/j.13990039.2007.00877.x

Lorcerie, B., Audia, S., Samson, M., Millière, A., Falvo, N., Leguy-Seguin, V., et al. (2017). Diagnosis of hyperferritinemia in routine clinical practice. Presse Med. 46, e329-e338. doi: 10.1016/j.lpm.2017.09.028

Lv, T., Zhang, W., Xu, A., Li, Y., Zhou, D., Zhang, B., et al. (2018). Non-HFE mutations in haemochromatosis in China: combination of heterozygous mutations involving HJV signal peptide variants. J. Med. Genet. 55, 650-660. doi: 10.1136/jmedgenet-2018-105348

Nie, L., Li, L., Yang, L., Zhang, Y., and Xiao, Z. (2010). HFE genotype and iron metabolism in Chinese patients with myelodysplastic syndromes and aplastic anemia. Ann. Hematol. 89, 1249-1253. doi: 10.1007/s00277-010-1016-z
Porto, G., Brissot, P., Swinkels, D. W., Zoller, H., Kamarainen, O., Patton, S., et al. (2016). EMQN best practice guidelines for the molecular genetic diagnosis of hereditary hemochromatosis (HH). Eur. J. Hum. Genet. 24, 479-495. doi: 10.1038/ejhg.2015.128

Powell, L. W., Seckington, R. C., and Deugnier, Y. (2016). Haemochromatosis. Lancet 388, 706-716. doi: 10.1016/S0140-6736(15)01315-X

Sohda, T., Okubo, R., Kamimura, S., and Ohkawara, T. (2001). Hemochromatosis with HFE gene mutation in a Japanese patient. Am. J. Gastroenterol. 96, 24872488. doi: 10.1111/j.1572-0241.2001.04058.x

Conflict of Interest: The authors declare that the research was conducted in the absence of any commercial or financial relationships that could be construed as a potential conflict of interest.

Copyright (c) 2020 Zhang, Wang, Duan, Xu, Zhao, Huang, You, Brissot, Ou and Jia. This is an open-access article distributed under the terms of the Creative Commons Attribution License (CC BY). The use, distribution or reproduction in other forums is permitted, provided the original author(s) and the copyright owner(s) are credited and that the original publication in this journal is cited, in accordance with accepted academic practice. No use, distribution or reproduction is permitted which does not comply with these terms. 